\title{
Formulation of mechanisms for gold-catalysed reactions *
}

\author{
Geoffrey Bond ${ }^{a}$ and the late David Thompson \\ www.goldbulletin.org
}

\begin{abstract}
The recent literature on simple gas-phase reactions involving $\mathrm{CO}, \mathrm{O}_{2}, \mathrm{H}_{2}, \mathrm{H}_{2} \mathrm{O}$ and $\mathrm{CO}_{2}$ catalysed by gold is surveyed and mechanisms derived from the literature are presented and analysed. They provide a template by which further results can be assessed and additional necessary study stimulated. Ways in which the published results can be used to develop catalysts with the necessary activity and stability for practical applications are indicated.
\end{abstract}

\section{Introduction}

The two decades following Haruta's discovery of the exceptional ability of gold in the finely divided state to effect the oxidation of $\mathrm{CO}$ at below ambient temperature $(1,2)$ have witnessed a remarkable growth in the exploration of its wider catalytic properties (3). Many of the reactions that it can catalyse are those of the five small molecules $\mathrm{CO}, \mathrm{O}_{2}, \mathrm{H}_{2} \mathrm{O}, \mathrm{H}_{2}$ and $\mathrm{CO}_{2}$ : these include not only the oxidation of $\mathrm{CO}$ and its selective oxidation in the presence of $\mathrm{H}_{2}$, but also the water-gas shift (WGS) and the synthesis of $\mathrm{H}_{2} \mathrm{O}_{2}$ and $\mathrm{CH}_{3} \mathrm{OH}$. This last reaction, involving the selective reduction of $\mathrm{CO}$ (3), has not yet been studied in detail with gold catalysts, and we therefore cannot consider it further at the moment. These are all processes of great industrial significance. The extensive research that has been performed on them has generated a mass of experimental results, not all of which are in agreement, and the catalytic activity and stability often depend sensitively on the method used for preparation and pre-treatment of the catalyst. For the above reactions, the principal factors determining performance are thoroughly appreciated: they include particle size and oxidation state of the gold, the chemical and physical form of the support, and the presence or absence of poisons and accelerators.

Since our own earlier essay in this direction (4), there have been important advances in defining the factors responsible for activity and stability, and the time is therefore ripe for a re-examination of the mechanisms of the simplest gold-catalysed reactions. There has been no previous attempt to look at this set of reactions together, or to provide a means of interpreting how the relevant determining factors listed above, and the effect of operating conditions, can be understood in atomic/molecular terms. In order to do this, we must first assemble as much information as we can on catalytic performance; we must also decide the best way to
* Abstract accepted for presentation at GOLD 2009, Heidelberg,

Germany, July 2009
9 Townfield, Rickmansworth WD3 7DD, UK

Tel: +44 1923774156 ,

E-mail: geoffrey10bond@aol.com 
present mechanistic ideas, and indeed to suggest exactly what constitutes 'a mechanism'.

The five molecules, reacting in different ways at different temperatures, will employ a limited number of intermediates of the type $\mathrm{CH}_{x} \mathrm{O}_{y}$ (formate, carboxyl, bicarbonate, carbonate etc, see Figure 1 ), and this simplifies the problem, but we cannot expect that all catalysts will operate in precisely the same way, or that unit steps common to several reactions will all proceed at the same speed. It is dangerous to imply that there is only one mechanism for the oxidation of $\mathrm{CO}$ (5). We must therefore try to see how the course of a reaction is conditioned by the physico-chemical parameters of the system.

Figure 1: Structures of adsorbed intermediates

$$
\begin{array}{cccc}
\mathrm{O}==\underset{\mathrm{C}}{\mathrm{C}}-\mathrm{OH} & & \mathrm{O}==\underset{\mathrm{C}}{\mathrm{C}}-\mathrm{O}^{-} & \mathrm{H}-\mathrm{C}==\mathrm{O} \\
{ }_{*}^{\mathrm{O}} & \mathrm{O}==\underset{\mathrm{C}}{\mathrm{C}}-\mathrm{OH} & \mid & \mathrm{O}_{*} \\
\text { bicarbonate } & \text { carboxyl } & \text { carbonate } & \text { formate }
\end{array}
$$

There are four principal legs on which a discussion of mechanism must stand: these are: [1] the state of the catalyst before and during use as revealed by analytical techniques (TEM, XAFS, XPS etc); [2] the kinetics of the reaction (orders of reaction, activation energy etc); [3] recognition of the adsorbed structures of reactants using FTIR etc; and [4] theoretical ideas, mainly derived from DFT. We shall unfortunately find that these four legs are rarely all simultaneously present; the frequent lack of kinetic information is particularly irksome. This point requires great emphasis, since no mechanistic proposal deserves serious consideration unless shown to be consistent with experimentally determined orders of reaction expressed in Langmuir-Hinshelwood formalism. Kinetic analysis quickly reveals whether two reactants chemisorb competitively or not, and enthalpies of adsorption under reaction conditions and true activation energy are easily estimated (6). There is difficulty of even arriving at definite conclusions concerning the importance of features such as particle size, oxidation state and support due to the variety of conditions under which activities have been measured (reactant ratio, moisture content, timeon-stream etc.). The situation is not helped by the frequent use of the totally inadequate temperature scan method for assessing activity; its limitations have been described in detail elsewhere $(3,6)$.
We shall not attempt a critical analysis of the contributions that density functional theory has made, not because they are irrelevant but because we lack the necessary competence.

Determination of the state of the catalyst while it is working, if it can be done, is vastly more informative than looking at it either before or after its use; its transformation during reaction, e.g. by reduction, is a real possibility. This probably explains why removal of metallic gold by cyanide washing led to the idea that cationic gold was the active species in the WGS (3); however it is now recognised that this form is reduced to very small metallic particles by the reactants and products.

Our analysis has nevertheless led to a number of proposals concerning the most likely mechanistic pathways undertaken during gold-catalysed reactions, particularly by small molecules in the gas phase, but we also suggest ways in which the depth and certainty of mechanistic understanding could be strengthened by appropriate experimentation. The utility of such information to the requirements of industrial and environmental application will be indicated.

The task that we address is neatly summarised by the following quotation from the writings of Max Planck: "The chief problem in every science is that of endeavouring to arrange and collate the numerous observations and details which present themselves, in order that they may become part of one comprehensive picture". To this task we now turn.

\section{Factors affecting the performance of gold catalysts}

The literature shows that a number of factors governing the performance of gold catalysts receive continual attention: these include (i) gold particle size, (ii) oxidation state of the gold, and (iii) choice of support and its nanocrystalline structure (7). The importance of particle size is very well established for $\mathrm{CO}$ oxidation, and the preferred methods of preparation strongly suggest that this holds for PROX and WGS as well. The mechanism of direct synthesis of $\mathrm{H}_{2} \mathrm{O}_{2}$ from $\mathrm{H}_{2}$ and $\mathrm{O}_{2}$ is less well defined but catalysts for obtaining high yields with $\mathrm{H}_{2}$ selectivities of $>95 \%$ have been recently described (8). The importance of oxidation state has also been more widely examined in $\mathrm{CO}$ oxidation, and the choice of support while relevant in all the reactions considered here appears to play a predominant role 
Figure 2: Variation of activity with particle size.

A

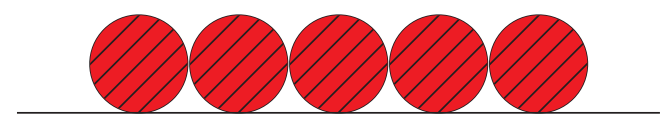

B
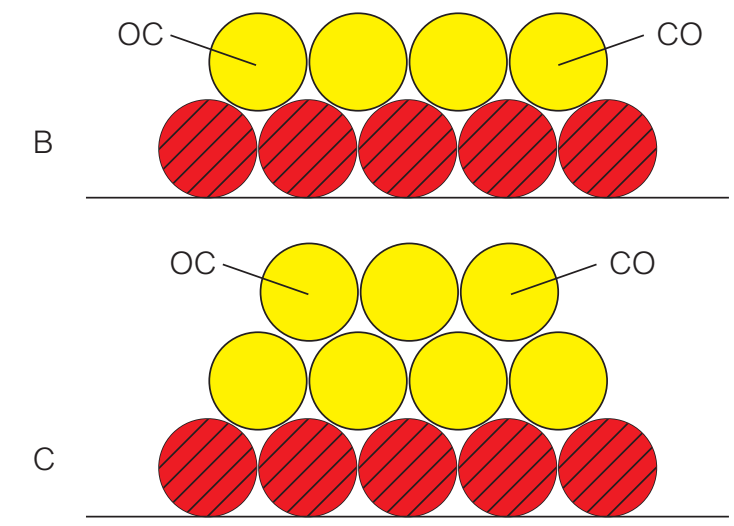

A: small particle, low or zero activity; B: bilayer particle, maximum activity; $C$, large particle, $\mathrm{CO}$ molecules too far from first layer, low activity

in WGS (9). However observing a correlation of rate with any variable is not the same as explaining its cause, and if we are to obtain a better understanding of mechanisms we need to ascertain as fully as possible how these factors operate. For example, numerous changes occur as the size of supported gold particles decreases, including lattice parameter, melting temperature, electronic structure, surface coordination numbers, length of perimeter, and many others. No single one of these is wholly responsible for the activity increase; what matters is how these factors acting in concert alter the mode and strength of binding of reactants, intermediates and products, because this is what activity depends on.
The belief is often expressed that external gold atoms in contact with the support differ in some significant way from the others, and those at the edge play a vital role in catalysis (10-12). It has recently been claimed that structures described as bilayers, having no more than two layers of gold atoms, have greater activity than either smaller (thinner) particles or larger multilayer particles for which many of the surface atoms are ineffective (13-15). Volumetric measurements show that the ratio of $\mathrm{CO}(\mathrm{ads})$ to $\mathrm{Au}$ (surface) is sometimes quite small ( 10-15\%) (16). A possible reason for this is suggested in Figure 2; it assumes that $\mathrm{CO}$ molecules are only adsorbed with sufficient stability on atoms of low coordination number, and that on large particles these are too distant from the first layer atoms to be useful. If indeed a particle of specific thickness is what is needed, it follows that the measurement of size in two dimensions as revealed by TEM is not the only important factor, and that quoting a mean size, as is frequently done, obscures the population of the special part of the distribution that contributes most to activity, e.g. that which bilayers inhabit. Not recognising this may explain the occasional failure of mean size to determine activity (17). The precise nature of the interaction between the gold and the oxide support is also of prime importance.

With model catalysts prepared by vapour-deposition of gold atoms onto $\mathrm{MgO}(100)$ (18) or $\mathrm{TiO}_{2}(110)$ (14) surfaces, the particles appear to become electronrich by electron transfer from F-centres on which they are nucleated; in this method $\mathrm{Au}^{0}$ atoms arrive at a dehydrated surface, and if mobile migrate to the nucleating centre. DFT calculations supporting this electron-transfer are based on imitation of this preparative method. However there is much evidence to suggest that cationic gold species are

Figure 3: Development of precursor layer in deposition-precipitation.

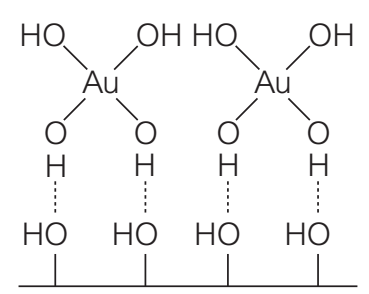

A

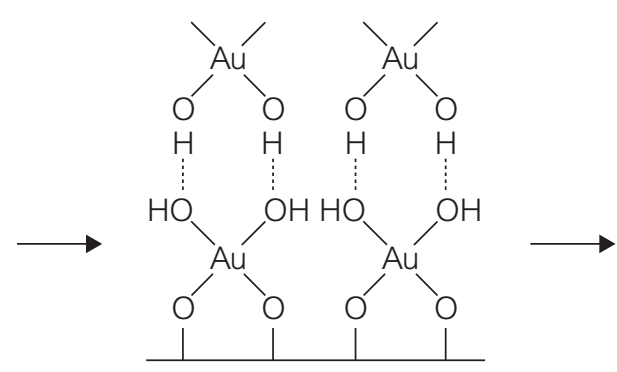

B

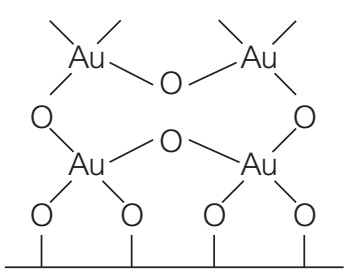

C

A: $\left[\mathrm{Au}(\mathrm{OH})_{4}\right]$ hydrogen-bonded to hyroxylated surface; B: water eliminated and second layer of $\left[\mathrm{Au}(\mathrm{OH})_{4}\right]$ hydrogen-bonded to first layer; C: more water eliminated and $\mathrm{Au}_{2} \mathrm{O}_{3}$ structure develops 


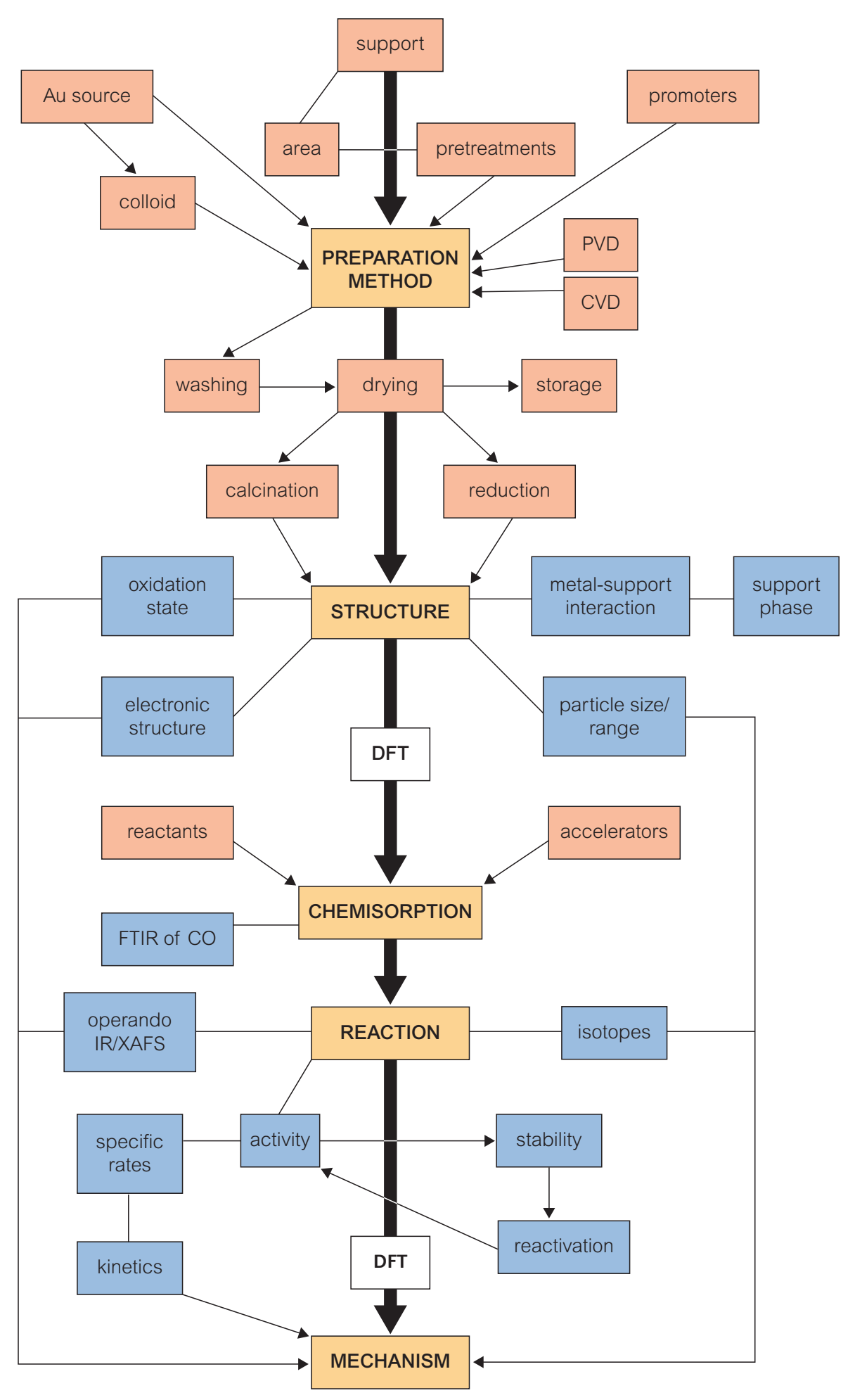

Factors bearing on the structure and performance of gold catalysts and on reaction mechanisms. Yellow boxes and bold lines: the principal parameters of a catalytic system that determine the mechanism, and their sequence; pink boxes: the main experimental variables that affect these parameters; blue boxes: the chief factors that need to be determined or methods that need to be applied in order to describe them 
required to assist the reaction (19), and that these may be preferentially found at the metal-support interface. It has been argued previously (4) that, with supported gold catalysts made by DP (Figure 3), the decomposition of the initial $\mathrm{Au}_{2} \mathrm{O}_{3}$ or $\mathrm{AuO}(\mathrm{OH})$ particle may leave a partial or complete layer of $\mathrm{Au}^{3+}$ ions at the interface (20); here the support surface is initially hydrated, and the formation of Au-Ti bonds as observed in model systems is unlikely. The retention of cations at the interface was indeed a feature of our earlier mechanism (4), and supporting evidence from other systems was introduced. Their detection may not be easy, as their maximum fraction will decrease with increasing size, and they may suffer reduction to $\mathrm{Au}^{0}$ during examination under UHV conditions. Furthermore the way of interpreting XAFS spectra has been questioned (19), as it is complicated by the environment of the absorbing atom. The desirable presence of cationic species also serves to explain the often-observed negative effect of calcination and high-temperature reduction on activity, although this may also be due to loss of the critical part of the size distribution by sintering. At least for $\mathrm{CO}$ oxidation such treatments are not needed (21). They probably also dehydrate the support surface, removing $\mathrm{OH}$ groups thought to be needed for good activity (see below).

We need to admit that, by seeking to understand how the various factors operate, we are walking on eggshells. Three reasons in particular need to be emphasised: [1] It is often implied that there is 'a mechanism' that is universally applicable to all gold catalysts for a given reaction (9). Depending on how 'a mechanism' is defined, this would seem improbable, as the support's contribution, whatever it is, will not be independent of its reducibility, and the rate-determining step will alter with temperature and reactant composition. We therefore have to

Figure 4: Various representations of an $\mathrm{OH}$ species bonded
to a gold atom
\begin{tabular}{|ccc|}
\hline I & I $\delta^{+} \delta^{-}$ & । \\
$-\mathrm{Au}-\mathrm{OH}$ & $-\mathrm{Au}-\mathrm{OH}$ & $-\mathrm{Au}^{+} \mathrm{OH}^{-}$ \\
covalent & | & | ionic \\
\hline
\end{tabular}

admit more than one mechanistic pathway (22). [2] In Scheme 1 we indicate the various inputs that lead via preparation method to structure to reaction to mechanism, but this does not emphasise how closely particle size, oxidation state and support may be interrelated. We have seen above how oxidation state may depend on particle size; it is now also clear that small particles can be partially oxidised by $\mathrm{O}_{2}$ (23) or even $\mathrm{CO}_{2}(24)$, so that oxidation state may vary with reaction conditions as hinted earlier. The high activity that $\mathrm{Au} / \mathrm{Al}_{2} \mathrm{O}_{3}$ catalysts can show is probably due to the ease with which very small particles $(<2 \mathrm{~nm})$ can be made; the rates are comparable with the best shown by $\mathrm{Au} / \mathrm{TiO}_{2}$ catalysts (see Table 1). [3] The detailed structure of adsorbed species may be represented in various ways that imply different degrees of oxidation of the metal (Figure 4); while gold has electronegative character, the extent to which electron-rich adsorbed species induce positive charge will depend on the gold atom's coordination number.

Although the existence of a 'support effect' is frequently claimed, the way in which it is exercised is far from clear. The first essential role of the support is however to stabilise particles against sintering, but this is rarely a problem except above $573 \mathrm{~K}$. It is however certain that gold particles can be modified by the support in ways that are either geometric (i.e. particle shape, degree of wetting of surface) or electronic (depending on the absence

Table 1: Activities of $\mathrm{Au}_{\mathrm{Al}} \mathrm{O}_{3}$ and Au/TiO $\mathrm{O}_{2}$ catalysts for $\mathrm{CO}$ oxidation

\begin{tabular}{|ccccccc|}
\hline Support & Method & {$[\mathbf{A u}] / \%$} & $\mathbf{d} / \mathbf{n m}$ & $\mathbf{T} / \mathbf{K}$ & $\mathbf{r}_{\mathbf{s p}} \mathbf{I m o l}_{\mathbf{c o}} \mathbf{g}_{\mathbf{A u}}{ }^{-1} \mathbf{s}^{-1}$ & References \\
\hline $\mathrm{Al}_{2} \mathrm{O}_{3}$ & $\mathrm{HDP}$ & 4.0 & 1.60 & 273 & $1.0 \mathrm{E}-4$ & 10 \\
" & $\mathrm{DAE}$ & 2.0 & $1.9-3$ & 373 & $1.8 \mathrm{E}-3$ & 25 \\
" & $\mathrm{DP}$ & 0.3 & $<1.4$ & 300 & $2.3 \mathrm{E}-3$ & 26 \\
$\mathrm{TiO}_{2}$ & $\mathrm{DP}$ & 1.16 & 1.2 & 298 & $7.1 \mathrm{E}-5$ & 27 \\
" & $\mathrm{MS}$ & 0.48 & 1.2 & 293 & $1.42 \mathrm{E}-3$ & 29 \\
& $\mathrm{DP}$ & 3.0 & 2.3 & 278 & $6.1 \mathrm{E}-4$ & 30 \\
\hline
\end{tabular}

$H D P=$ homogeneous deposition-precipitation with $\left[\mathrm{Au}\left(\mathrm{NH}_{3}\right)_{4}\right]\left(\mathrm{NO}_{3}\right)_{3}$

$D A E=$ direct anion exchange; $D P=$ deposition-precipitation; $M S=$ magnetron sputtering 
of any insulating layer at the interface). They can also affect the properties of the support, seen most clearly by easier reduction of supports such as $\mathrm{CeO}_{2}$ (31) and $\mathrm{Fe}_{2} \mathrm{O}_{3}$; with the former the interaction between metal and oxide can be quite complex, with $\mathrm{Au}^{3+}$ ions entering the oxide lattice and creating additional anion vacancies and easier $\mathrm{O}^{2}$ - mobility $(32,33)$. With oxide supports that are to some degree reducible under pre-treatment or reaction conditions (i.e. by $\mathrm{CO}$ or $\mathrm{H}_{2}$ ) the resulting anion vacancies close to gold particles have been suggested as the locus of oxygen adsorption and activation (4); this will not happen to any significant extent with the ceramic oxides $\left(\mathrm{MgO}, \mathrm{SiO}_{2}, \mathrm{Al}_{2} \mathrm{O}_{3}\right)$, so that gold on these supports must rely on another type of mechanism for its activity. Other aspects of the support that influence performance include (i) surface area (34), (ii) particle size, and (iii) crystal habit.

A significant development in our appreciation of mechanisms for gold-catalysed reactions has been the recognition of the importance of water and hydroxyl groups (35-38). These were assigned a role in our earlier mechanism (4) as a means of facilitating $\mathrm{CO}$ oxidation through the formation of a $\mathrm{CO} . \mathrm{OH}$ intermediate, but it now appears that they have a wider task in preventing the formation of toxic inhibitors such as $\mathrm{CO}_{3}^{2-}$ and $\mathrm{HCO}_{3}{ }^{-}$, or removing them when once formed (39) (see Figure 1 for the structures of adsorbed intermediates). There are indications that deactivation of $\mathrm{CO}$ oxidation is at least partly due to a diminution of $\mathrm{OH}^{-}$concentration (40), allowing the growth of toxic species, and the loss of $\mathrm{OH}^{-}$groups may be an additional reason for avoiding calcination. We should expect to find a correlation between calcination temperature and catalytic activity that reflects the stability of $\mathrm{OH}^{-}$ groups on the support or on the gold itself, but no systematic studies seem to have been made (41). While a low water concentration is helpful (37), too much can apparently block active sites and decrease activity (42). Its positive effect is greater with $\mathrm{Au} / \mathrm{Al}_{2} \mathrm{O}_{3}$ than with $\mathrm{Au} / \mathrm{TiO}_{2}$ (36), perhaps because in the former case the support $\mathrm{OH}^{-}$groups are stabler and less able to participate in reaction, so that $\mathrm{Au} / \mathrm{Al}_{2} \mathrm{O}_{3}$ derives more benefit from water molecules chemisorbed on or close to gold particles than does $\mathrm{Au} / \mathrm{TiO}_{2}$, where the required $\mathrm{OH}^{-}$groups are more readily available.

In the selective oxidation of $\mathrm{CO}$ in the presence of excess $\mathrm{H}_{2}$ (PROX), some water is inevitably formed, and it (or an $\mathrm{OH}^{-}$group derived from it) assists in maintaining activity by controlling formation of $\mathrm{CO}_{3}{ }^{2-}$ and $\mathrm{HCO}_{3}^{-} \cdot \mathrm{H}_{2}$ is however less effective than water in preventing deactivation $(27,43)$, perhaps because it has first to be converted to water in order to work; its effect on $\mathrm{CO}$ oxidation over $\mathrm{Au} / \mathrm{TiO}_{2}$ has been confirmed by operando IR (43) Water is of course a reactant in WGS, but using it to oxidise CO and to release $\mathrm{H}_{2}$ demands a higher temperature regime than works for $\mathrm{CO}$ oxidation and PROX, although there are similar features. For example, it now seems likely that the carboxyl group $(-\mathrm{COOH})$ is the key intermediate in both reactions (33), and that in WGS in the absence of $\mathrm{O}_{2}$ it decomposes directly to $\mathrm{CO}_{2}$ and $\mathrm{H}_{2}$.

\section{The formulation of reaction mechanisms}

It is very desirable for a number of reasons that any study of a catalytic system should finish with the proposal of a reaction mechanism. Apart from the intellectual satisfaction afforded by finding a model for the reaction that accommodates and rationalises most if not all the observed facts, a mechanism should point the ways in which performance might be further improved, and should predict how this might change in conditions beyond those actually used. A problem arises however because there are differing views on what constitutes a satisfactory representation of a reaction mechanism. This difficulty is common to many studies in heterogeneous catalysis, but is particularly so with gold catalysts because of the number of possible ambiguities in interpreting the observations. A glance at the literature reveals that the modes of expression used and the degree of detail found acceptable vary very widely; this divergence has been highlighted in recent publications $(3,6)$. It is strange that scientists, trained to be precise, abandon precision when faced with the task of devising a mechanism. There is as yet no agreed protocol as to what a mechanism should contain; this is a matter we must now address.

Attaining the essential core of any mechanism requires us to visualise the progress of the reaction through a model that operates at the atomic/molecular level. It is important to appreciate that the depth of understanding achievable depends on the terms used to construct the model. This consideration has been summarised as follows (44): "The kind of answer we get depends upon the language in which the question is framed; its value is determined by the care that has gone into defining the nature of the conceptual model and by the symbolism employed to express it". So for example the use of symbols to represent elements disguises the fact that the 
$\mathrm{H}$ atom is much smaller than the gold atom, and ignoring this can lead to suggesting reactions that are sterically unlikely.

In order to make progress we have therefore to list the desirable inputs into any idea of a mechanism, to assess their relative importance, and to examine how far previous proposals have gone in utilising them. The diversity of suggestions for such a seemingly straightforward reaction as $\mathrm{CO}$ oxidation implies that all the relevant facts are not always employed, even when they are available. To construct a mechanism we need the following:

- As much information as possible about the state of the catalyst while working (particle size and oxidationstate of the Au, reduction/dehydroxylation of the support, location of promoters etc.)

- Information on the state of the adsorbed reactants, intermediates and products, whether on the Au or the support.

- Most importantly, information on the kinetics (specific rates or TOFs, orders of reaction including product inhibition, apparent activation energy, rate of deactivation etc.); this is essential to locate the rate-determining step.

Other pertinent input for obtaining a complete picture will include the effect of accelerators, especially water, and ways in which lost activity may be restored. The application of theory, especially DFT, may provide insights into the likely state of affairs in the reaction, but it is unlikely that theory alone can rise above the level of informed speculation.

It has been suggested (44) that at an elementary level a mechanism is understood if the following are established beyond reasonable doubt:

- The nature of all the participating species.

- The qualitative modes of their interactions contributing significantly to the total reaction.

- Quantitative aspects of these interactions expressed on a relative if not an absolute basis.

This requires there to be set down a series of unit steps by which the reaction is thought to proceed, conveying as much information as possible about the location of the adsorbed intermediates and any significant electrical charge involved. Summation of these steps should lead to a cancellation of all the intermediates, excepting those leading to inhibition, leaving only the stoichiometric reaction. These steps can be shown as a catalytic cycle, or typographically.

This is just the beginning, because two further actions are needed. First, the steps have to be displayed in a spatially and sterically informative way, to ensure that each of them appears feasible by these criteria. This requires the atoms to be shown in about the correct relative sizes, rather than by symbols, but accurate transformation of the three-dimensional situation into a two-dimensional picture is not easy and is rarely attempted. Second, very importantly, the set of unit steps has to be composed into a kinetic expression based on a rate-determining step that leads to a predicted dependence of rate on reactant concentrations in conformity with the observed orders of reaction. This analysis can in favourable circumstances take us via the temperature-dependence of (i) the rate constant to the true activation energy, and (ii) the adsorption coefficients to the enthalpies of adsorption (45). It is however impossible to apply these two actions to all the reactions we have considered, especially because in the second case there is not enough experimental evidence to compare with theoretical predictions. What we can do is to propose reactions schemes for $\mathrm{CO}$ oxidation catalysed by gold on three classes of oxide support, and indicate their extension to cover (i) the effects of $\mathrm{H}_{2}$ and water, and (ii) ways of deactivating and reactivating catalysts. In doing this we lean on suggestions made in the literature, all of which are either incomplete (35), oversimplified (46), over-complicated (38) or otherwise unsatisfactory (47) in some way. We have developed the Kung scheme for $\mathrm{Au} / \mathrm{Al}_{2} \mathrm{O}_{3}$ (35) in the expectation that it might apply to other ceramic oxides, and have extended our own original proposal for oxides that are slightly reducible. A modified Mars-van Krevelen mechanism (48) involving support lattice oxide ions may apply to more easily reducible oxide supports (e.g. $\mathrm{CeO}_{2}, \mathrm{Fe}_{2} \mathrm{O}_{3}$ ).

The essence of the Kung scheme for $\mathrm{Au} / \mathrm{Al}_{2} \mathrm{O}_{3}$ (Scheme 2) is that in an initiating step an $\mathrm{Au}-\mathrm{OH}$ species is formed perhaps at a peripheral gold atom or ion $\left(\mathrm{Au}_{\mathrm{a}}\right.$ or $\left.\mathrm{Au}_{\mathrm{a}}^{+}\right)$by transfer of a support hydroxide ion; the exact manner of its formation was not made clear (35), and remains to be elucidated. This species is re-formed in the reaction cycle, thus acting catalytically, and any process that destroys it will deactivate the catalyst. It reacts with a CO molecule adsorbed on a low-coordination gold atom $\left(\mathrm{Au}_{\mathrm{b}}\right)$ to form a carboxyl group which is further oxidised to bicarbonate; provided this decomposes to form $\mathrm{CO}_{2}$ the cycle is completed, but if it is oxidised to carbonate the cycle is broken, and the action of water is needed to decompose it and restore the cycle (left-hand part of Scheme 2). The promoting action of $\mathrm{H}_{2}$ (43) is explained as providing an additional route to $\mathrm{Au}-\mathrm{OH}$ and to $\mathrm{Au}-\mathrm{O}$ 
(right-hand part of Scheme 2). Note that the cycle can only form one $\mathrm{CO}_{2}$; a second iteration is needed to use the second oxygen atom, and this Scheme therefore assumes dissociation of oxygen molecules on $\mathrm{Au}_{\mathrm{b}}$ atoms (see foot of Scheme 2). This Scheme therefore accounts for the major observations made with $\mathrm{Au} / \mathrm{Al}_{2} \mathrm{O}_{3}$.

The essential features of our original mechanism for the reaction over gold on $\mathrm{TiO}_{2}$ or other reducible oxides (4) are reproduced in Scheme 3; they differ from those in Scheme 2 in the consequence of forming the catalytic Au-OH species by borrowing an $\mathrm{OH}^{-}$ion from the support; this results in a $\mathrm{Ti}^{3+}$ ion, since

$$
\mathrm{OH}_{\mathrm{s}}^{-}+\mathrm{Au}_{\mathrm{a}}+\mathrm{Ti}^{4+} \rightarrow \mathrm{Au}_{\mathrm{a}}-\mathrm{OH}+\square_{\mathrm{s}}+\mathrm{Ti}^{3+}
$$

and the resulting anion vacancy provides the locus for the adsorption of an oxygen molecule as $\mathrm{O}_{2}$ :

$$
\mathrm{\square}_{\mathrm{s}}+\mathrm{Ti}^{3+}+\mathrm{O}_{2} \rightarrow \mathrm{O}_{2}^{-} \mathrm{a}_{\mathrm{s}}+\mathrm{Ti}^{4+}
$$

(see foot of Scheme 3). The effect of $\mathrm{H}_{2}$ is to make more of the peroxy species Au-OOH (left-hand part of Scheme 3), while a similar route is proposed for forming and destroying carbonate ion (right-hand part of Scheme 3). Adsorbed CO enters the cycle at two points, and the stoichiometric reaction is completed in a single iteration. If and when $\mathrm{HCO}_{3}$ (bicarbonate) is formed from $\mathrm{CO}_{2}$ and $\mathrm{OH}_{\mathrm{s}}{ }^{-}$(37), it either decomposes by the reverse reaction or is oxidised to $\mathrm{CO}_{3}{ }^{2-}$ and $\mathrm{OH}_{\mathrm{s}}$; ; it is not therefore an intermediate in the main cycle but a precursor to a toxin. Our own Scheme requires non-competitive

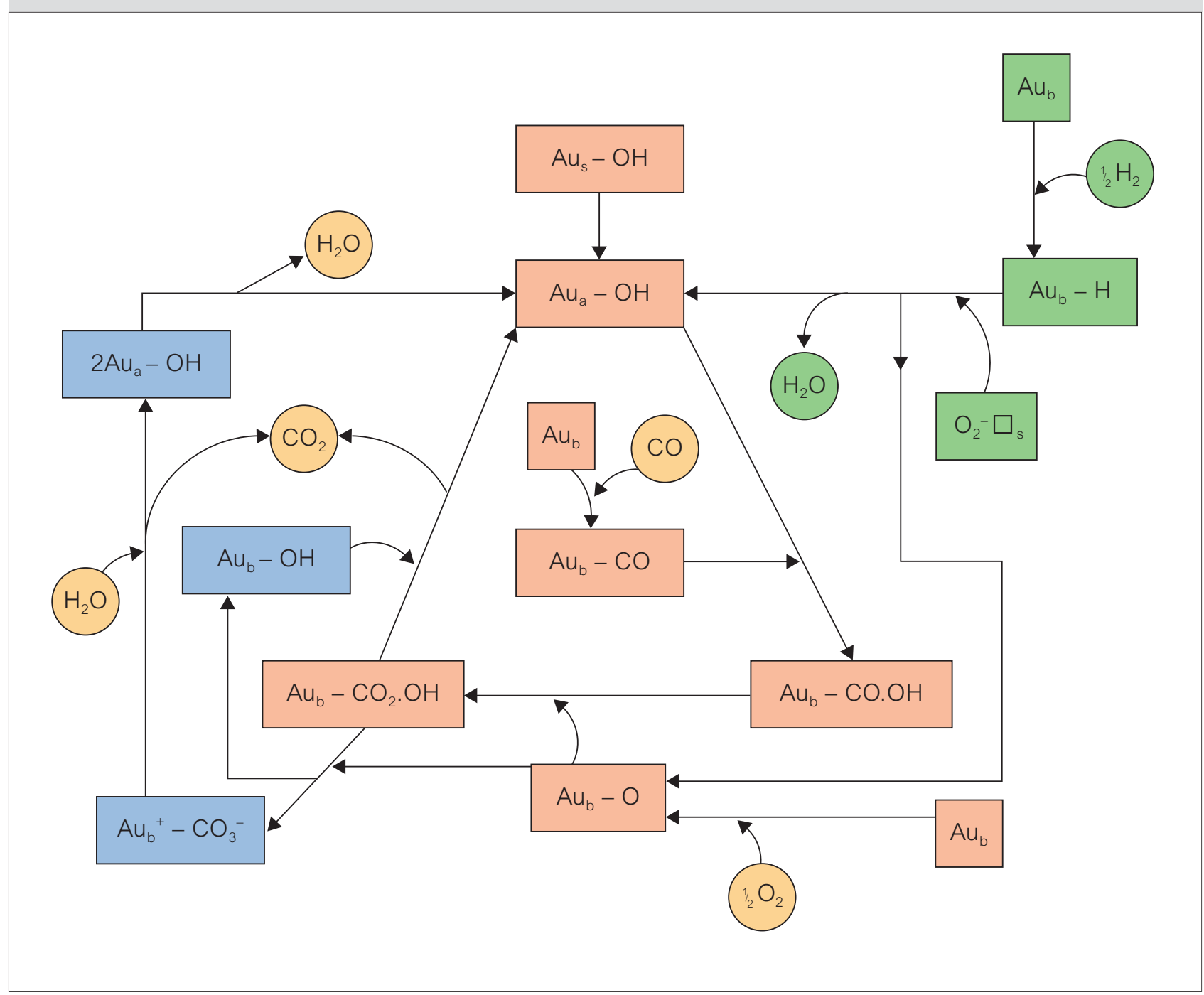

Catalytic cycle for $\mathrm{CO}$ oxidation on $\mathrm{Au} / \mathrm{Al}_{2} \mathrm{O}_{3}$ (based on ref. 35). Reactants and products are in yellow circles, intermediate species in the main cycle in pink boxes, species associated with the formation and removal of toxic carbonate in blue boxes, and species arising from the presence of $\mathrm{H}_{2}$ in green boxes 


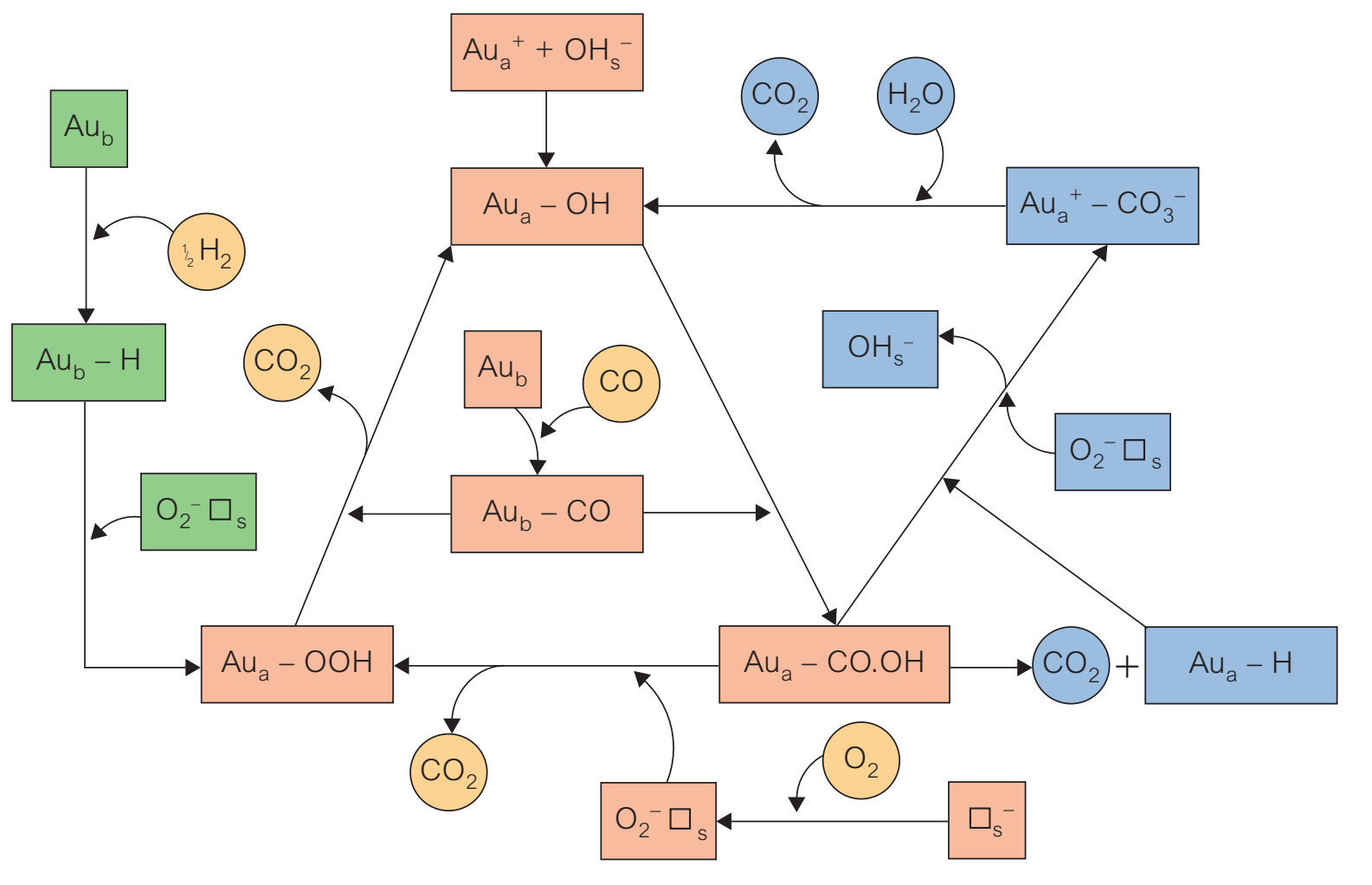

Catalytic cycle for CO oxidation on reducible oxides (based on ref. 4). The significance of the colours is as in Scheme 2

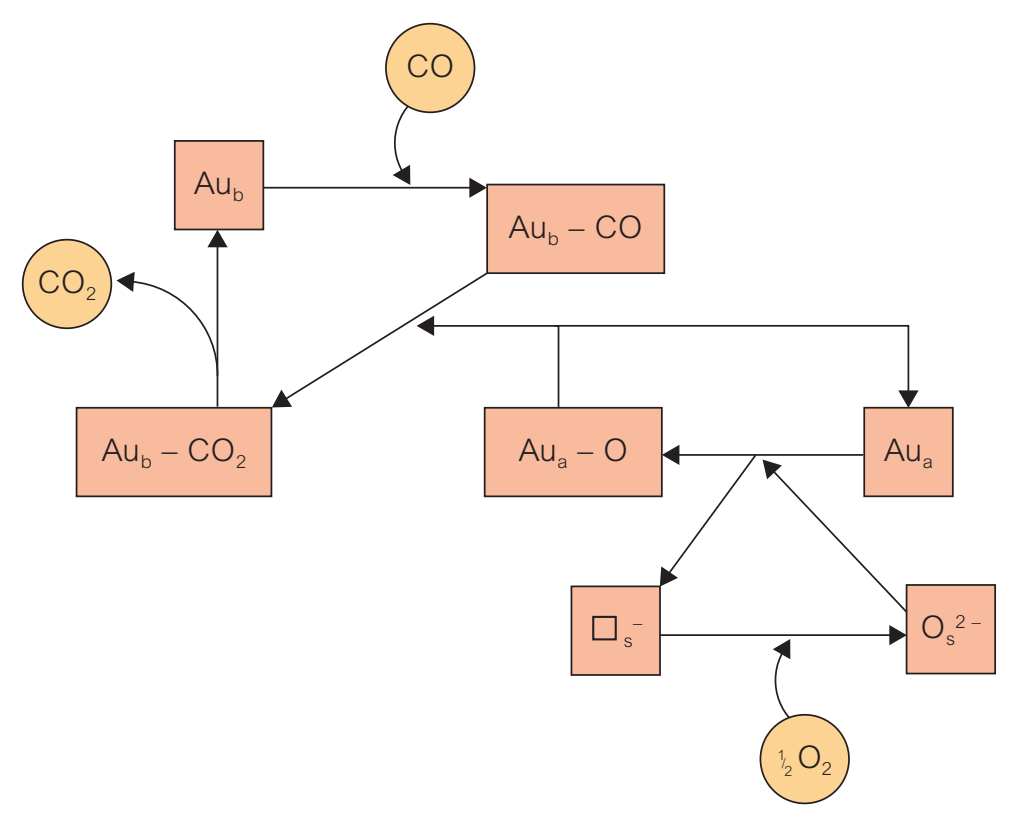

Catalytic cycle for CO oxidation by a redox mechanism (Mars-van Krevelen mechanism, see ref. 48). The use of the colours is as in Scheme 2 
adsorption of the reactants, which is supported by Vannice's kinetic analysis of $\mathrm{CO}$ oxidation on $\mathrm{Au} / \mathrm{TiO}_{2}$ (42), whereas with the Kung Scheme 2 the reactants could use either the same type of site (as shown) or different ones.

In these schemes the inhibiting species is portrayed as the carbonate ion formed by oxidation of either $\mathrm{Au}-\mathrm{COOH}$ (Scheme 3) or Au- $\mathrm{CO}_{2} . \mathrm{OH}$ (Scheme 2); the suggestion that the toxin is bicarbonate formed from $\mathrm{CO}_{2}(24,37)$ is easily accommodated in Scheme 3, but not in Scheme 2, which would require modification if it applied in this case.

Finally we illustrate in Scheme 4 the basic Mars-van Krevelen mechanism (48), which uses only lattice $\mathrm{O}_{2}^{-}$ ions as oxidant. It seems unlikely that this is ever the only mechanism, even with easily reducible supports, since it has no provision for water or $\mathrm{OH}^{-}$groups to assist the reaction. However there have been several suggestions that this mechanism could make a contribution, and it may well accompany either of the other mechanisms in favourable circumstances.

\section{Interpreting the observations; the simplicity principle}

It will be obvious from the forgoing as well as from recent reviews $(3,6)$ that each group has its own ideas of what constitutes an adequate representation of a mechanism, and of the amount and type of experimental information that is needed to formulate it. This is not surprising, because each group has been exposed to a different mixture of cultural impacts that affect its perception of the proper conclusions to be drawn from the observations. This imposition has long been recognised, and was clearly expounded by Francis Bacon, Earl of Verulam, writing in about AD 1620 (49). He identified four 'Idols of the Mind' that interfere with the process of drawing conclusions.

- Idols of the Tribe: "Human understanding distorts the nature of things by mingling its own nature with it". Thus, he noted, there is a universal propensity to over-simplification, which led Einstein to warn that "We must make things as simple as possible - but not simpler."

- Idols of the Cave: "Prejudices which result from our own particular upbringing, education, and experience." Thus, he said, one concentrates on likenesses, another on differences; one on detail, another on the whole.

- Idols of the Market Place: "These result from our interaction with others, where the ill and unfit choice of words wonderfully disturbs the understanding." So, he thought, errors may even stem from the language used.

- Idols of the Theatre: "These are the many principles and axioms of science that by tradition, credulity and negligence have come to be received." Science, he said, only makes progress through discovery.

It requires little effort to see the relevance of these Idols to the problem of formulating reaction mechanisms; they constitute a pithy summary of the pitfalls we must try to avoid, and they merit a fuller exposition than is possible here.

While over-simplification is not recommended, neither is over-complication. Some proposed mechanisms are so complex, requiring a number of unit steps to occur in close sequence, that they cannot be easily represented as a set of sequential processes or as a catalytic cycle. Recalling Einstein's belief (see above), we should doubt the reality of such mechanisms. Indeed the merits of adopting the simplest possible explanation for physical phenomena were recognised by the earliest philosophers of science, one of the best known of which is William Occam ( AD 1300) who stated that "Entities are not to be multiplied unnecessarily." Occam's Razor, as it is now known, is a useful principle to apply when trying to decide which mechanism is the more appropriate.

\section{The importance of understanding mechanisms to practical applications}

Mechanistic schemes of the type shown above provide a framework for interpreting new discoveries as they are made, and for suggesting profitable lines for further research and development. The ability of gold powder to catalyse $\mathrm{CO}$ oxidation in the aqueous phase at $\mathrm{pH} 14$ and $300 \mathrm{~K}$ (50) is readily understandable through the need established by gas phase studies with supported catalysts $(24,37,39)$, as shown in Schemes 2 and 3 to have an adequate concentration of $\mathrm{OH}^{-}$groups to assist the reaction and prevent formation of toxic carbonate-like species. The beneficial effect of pretreating titania at $\mathrm{pH} 10$ (28) to ensure full hydroxylation of the surface before depositing the gold by magnetron sputtering for gas-phase studies is similarly explained (see Table 1): the catalyst was then stable for $120 \mathrm{~h}$. Activity and stability for $\mathrm{CO}$ oxidation can be improved by using multicomponent supports, the essential component being a readily reducible oxide such as $\mathrm{SnO}_{2}$ (51) or $\mathrm{Fe}_{2} \mathrm{O}_{3}$ that produces a source of anion vacancies 
under reaction conditions; these are needed for our mechanism (Scheme 3) as sites for $\mathrm{O}_{2}$ adsorption, but they may also act as a sources of $\mathrm{OH}$ groups to maintain activity. Gold supported on a mixed iron oxide-alumina support has shown exceptional stability for CO oxidation, and finds application in gas mask technology. The beneficial effects of the presence of water on the $\mathrm{CO}$ oxidation activity of $\mathrm{Au} / \mathrm{TiO}_{2}$ mean that smaller and more durable respirators can be made with gold catalysts than with hopcalite $(37,52-54)$.

Since the $\mathrm{OH}$ - ion is a one-electron reductant, the support cation needs to have an oxidation state one below the maximum (e.g. $\mathrm{Fe}^{2+}$ from $\mathrm{Fe}^{3+}, \mathrm{Ce}^{3+}$ from $\mathrm{Ce}^{4+}$, etc.), so that oxides such as $\mathrm{NiO}$ and $\mathrm{ZnO}$ that do not have this, and that may also be deficient in $\mathrm{OH}$ groups, will therefore in general be less effective as supports. This criterion for ease of reduction was established many years ago in the context of metal-hydrogen spillover (55). The well established effects of support particle size as shown for example by nano- $\mathrm{CeO}_{2}(7)$ are likely also due to improved ease of support reduction.

The water-gas shift (WGS) (9) provides an excellent example of the importance of correct choice of support, although gold particle size is also important. Consideration of likely reaction mechanisms strongly suggests that activation of the water molecule through anion vacancies close to the Au particles is the essential step, as the more easily reducible $\mathrm{CeO}_{2} \mathrm{CeZrO}_{4}$ and $\mathrm{Fe}_{2} \mathrm{O}_{3}$ make the best supports. The important role played by anion vacancies is thus a recurring theme throughout gold catalysis where oxide supports are used, although the use made of them depends on the reaction. The idea (33) that $\mathrm{CO}_{2}$ formation in WGS might be more economically achieved by decomposition of an $\mathrm{Au}-\mathrm{COOH}$ intermediate than by its reaction with an $\mathrm{OH}$ species leads to the thought that the decomposition of formic acid, which also affords $\mathrm{CO}_{2}$ and $\mathrm{H}_{2}$ might provide a simple model reaction for assessing WGS activity. Sulfated zirconia has been claimed as an effective support for a stable gold catalyst for WGS (56); the strongly acidic surface would help to polarise the water molecule in readiness for its dissociation on an anion vacancy. We intend to develop these thoughts more fully in a further paper (57).

The mechanism of the synthesis of $\mathrm{H}_{2} \mathrm{O}_{2}$ has likewise not been treated in detail, but reviews of the recent extensive experimental work are available (58-60). The left hand part of Scheme
III suggests that the reaction proceeds via an Au$\mathrm{OOH}$ species, and that the $\mathrm{O}-\mathrm{O}$ bond is not broken in the reaction; indeed if it does break, i.e. if the molecule is dissociatively adsorbed, formation of water is the inevitable outcome (61). Procedures such as acid-treatment of a carbon support (8) for $\mathrm{H}_{2} \mathrm{O}_{2}$ synthesis must therefore work by minimising $\mathrm{O}-\mathrm{O}$ bond dissociation. It is surprising that research on selective reactions does not focus more on seeking catalysts that are inactive for the unwanted reaction(s). Thus, identifying features capable of avoiding catalysis of the decomposition of $\mathrm{H}_{2} \mathrm{O}_{2}$ and inactive for water formation should assist in the search for the best $\mathrm{H}_{2} \mathrm{O}_{2}$ synthesis catalysts. Gold-palladium catalysts perform better than either metal alone (56-60), an observation that has not yet been fully explained; it could be of interest to try this combination for WGS. Old work on reactions of hydrogen (61) shows that adding gold to palladium often improves its activity.

The 3M PROX catalysts that are very stable, have a long shelf life and provide high levels of $\mathrm{CO}$ oxidation activity for extended times without being active for $\mathrm{H}_{2}$ oxidation to water, are prepared by physical vapour deposition of gold under oxidising conditions, and contain various oxide additives $(62,63)$.

\section{Conclusions}

A survey of the literature on the gold-catalysed reactions of small molecules concludes that the nature of the support, its particle size and state of reduction determine activity and influence reaction mechanisms. We have attempted to suggest mechanisms that fit with the experimental results, including schemes for $\mathrm{CO}$ oxidation and PROX for (a) ceramic oxides (Scheme 2), and (b) reducible oxides (Scheme 3). Deactivation is caused by formation of carbonate/bicarbonate species rather than by gold particle sintering, which does however play a role at the higher temperatures that WGS requires (57). This need may be due to the more difficult activation of water on reduced support surfaces.

The mechanisms proposed are broadly consistent with experimental observations, but should be regarded as 'work in progress', requiring extension and modification as new facts emerge. They do, however provide a template by which our understanding of mechanisms can be assessed, and they suggest aspects requiring additional 
study in order to achieve further improvements. Researchers are strongly encouraged to obtain the necessary information on which mechanisms can be more firmly based, and to devote careful thought to the full presentation of their concepts of how reactions proceed.

\section{About the authors}

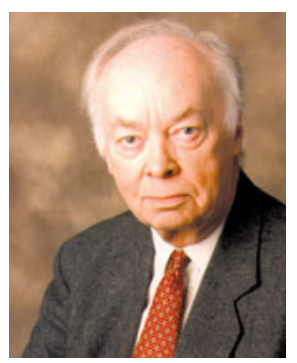

Geoffrey Bond held academic posts at Leeds and Hull Universities before joining Johnson Matthey plc in 1962 as Head of Catalysis Research. In 1970 he was appointed Professor in Brunel University Chemistry Department, and is now an Emeritus Professor at that University.

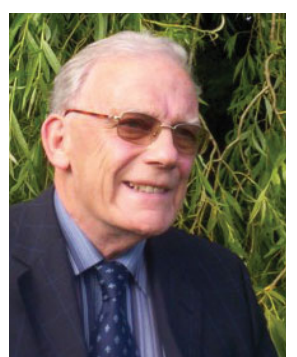

David Thompson had a special interest in catalysis by gold, having previously held research posts in $\mathrm{ICl}$ and Johnson Matthey plc where he was involved in precious metal catalysis projects. He was also consultant to World Gold Council in London and Project AuTEK at Mintek in South Africa. He died on 17 June 2009.

\section{References}

1 M. Haruta, T. Kobayashi, H. Sano and N. Yamada, Chem. Lett., 1987, 2, 405

2 M. Haruta, N. Yamada, T. Konayahi and S. Iijima, J. Catal., 1989, 115, 301

3 G.C. Bond, C. Louis and D.T. Thompson, Catalysis by Gold, Imperial College Press, 2006

4 G.C. Bond and D.T. Thompson, Gold Bull., 2000, 33, 41

5 G.J. Hutchings, J. Chem. Soc., Dalton Trans., 2008, 5523

6 G.C. Bond, Cat. Rev. - Sci. Eng., 2008, 50, 532

7 S. Carretin, P. Concepcion, A. Corma, J.M. Lopez-Nieto and V.F. Puntes, Angew. Chem. Int. Ed., 2004, 43, 2538

8 J.K. Edwards, B. Solsona, E.N. N, A.F. Carley, A.A. Herzing, C.J. Kiely and G.J. Hutchings, Science, 2009, 323, 1037

9 R. Burch, Phys. Chem. Chem. Phys., 2006, 8, 5483

10 T.V.W. Janssens, A. Carlsson, A. Puig-Molina and B.S. Clausen, J. Catal., 2006, 240, 108

11 M.Okumura, S. Nakamura, S. Tsubota, T. Nakamura, M. Azuma and M. Haruta, Catal. Lett., 1998, 51, 53

12 N.Ossipoff and N.W. Cant, Topics Catal., 1999, 8, 161

13 A.A. Herzing, C.J. Kiely, A.F. Carley, P. Landon and G.J. Hutchings, Science, 2008, 321, 1331; G.J. Hutchings, J. Mater. Chem., 2009, 19, in press
14 M. Chen and D.W. Goodman, Chem. Soc. Rev., 2008, 37, 1860

15 N.C. Hernández, J.F. Sanz and J.A. Rodriguez, J. Am. Chem. Soc., 2006, 128, 15600

16 F Menegazzo, F Pinna, M.Signoretto, V Trevisan, F Boccuzzi, A Chiorino and M Manzoli, Appl. Catal. A:Gen., 2009, 356, 31; ChemSusChem, 2008, 1, 320

17 S.H. Overbury, V. Schwartz, D.R. Mullins, W.-F. Yan and S. Dai, J. Catal., 2006, 241, 56

18 O. Meerson, G. Sitja, and C.R. Henry, Eur. Phys. J.:D, 2005, 34119

19 J.C. Fierro-Gonzalez and B.C. Gates, Chem. Soc. Rev., 2008, 37, 2127; Catal. Today, 2007, 122, 201

20 G.J. Hutchings, M.S. Hall, A.F. Carley, P. Landon, B.E. Solsona, C.J. Kiely, A. Herzing, M. Makkee, J.A. Moulijn, A. Overweg, J.C, Fierro-Gonzalez,

J. Guzman and B.C. Gates, J. Catal., 2006, 242, 71

21 F. Moreau, G.C. Bond and A.O. Taylor, J. Catal., 2005, 231, 105

22 F. Boccuzzi, A. Chiorino, S. Tsubota and M. Haruta, J. Phys. Chem., 1996, 100, 3625

23 J.A. van Bokhoven, C. Louis, J.T. Miller, M. Tromp, O.V. Safanova and P. Glatzel, Angew. Chem. Int. Ed., 2006, 45, 4631

24 K.M. Parida, P. Mohapatra, J. Moma, W.A. Jordaan and M.S. Scurrell, J. Molec. Catal.A: Chem. 2008, 288, 125

25 S. Ivanova, V. Pitchon and C. Petit, J. Molec. Catal.A: Chem., 2007, 272, 306

26 N. Weiher, E. Bus, R. Prins, L. Delannoy, C. Louis, D.E. Ramaker, J.T. Miller and J.A. van Bokhoven, J. Catal., 2006, 240, 100

27 J.Y. Calla and R.J. Davis, Ind. Eng. Chem. Res., 2005, 44, 5403

28 G.M. Veith, A. Lupini and R.J. Dudney, J. Phys. Chem. C, 2009, 113, 269

29 R. Zanella, S. Giorgio, C.-H. Shia, C.R. Henry and C. Louis, J. Catal., 2004, 222, 357

30 J.T. Calla, M.T. Bore, A.K. Datye and R.J. Davis, J. Catal., 2006, 238, 458

31 S.-P. Wang, T.-Y. Zhang, X.-Y. Wang, S.-M. Zhang, S.-R. Wang, W.-P. Huang and S.-H. Wu, J. Molec. Catal. A: Chem., 2007, 272, 45

32 A.M. Venezia, G. Pantaleo, A. Longo, G. DiCarlo, M.P. Casaletto, F.L. Liotta and G. Deganello, J. Phys. Chem. B, 2005, 109, 2821

33 C.-J. Zhang, A. Michaelides, D.A King and S.J. Jenkins, J. Chem Phys., 2008, 129, 194708

34 F. Moreau and G.C. Bond, Catal Today, 2007, 122, 215

35 C.K. Costello, J.H. Yang, H.Y. Law, Y. Wang, J.-N. Liu, L.D. Marks, M.C. Kung and H.H. Kung, Appl. Catal. A: Gen., 2003, 243, 15

36 Eun Duck Park and Jae Sung Lee, J. Catal., 1999, 186, 1

37 T.A. Ntho, J.A. Anderson and M.S. Scurrell, J. Catal., 2009, 261, 94 
38 S.T. Daniells, A.R. Overweg, M. Makkee and J.A. Moulijn, J. Catal., 2005, 230, 52

39 M.Daté, M. Okumura, S. Tsubota and M. Haruta, Angew. Chem. Int. Ed., 2004, 43, 2129

40 H.-S. Oh, C.K. Costello, C. Cheung, H.H. Kung and M.C. Kung, Stud. Surf. Sci. Catal., 2001, 139, 375

41 M. Daté, Y. Ichiyashi, T. Yamashita, A. Chiorinio, F. Boccuzzi and M. Haruta, Catal. Today, 2002, 72, 89

42 M.A. Bollinger and M.A. Vannice, Appl. Catal. B:Env.,1996, 8,417

43 E. Quinet, F. Morfin, F. Diehl, P. Avenier, V. Caps and J.-L. Rousset, Appl. Catal. B: Env, 2008, 80, 195;

L. Piccolo, H. Daly, A. Valcarel and F.C. Meunier, Appl. Catal B:Env, 2009, 86, 190

44 G.C. Bond and P.B. Wells, Adv. Catal., 1964, 15, 92 ; see also G.C. Bond, Metal-Catalysed Reactions of Hydrocarbons, Springer, New York, 2005, and ref. 6

45 G.C. Bond, F. Rosa C. and E.L. Short, Appl. Catal. A: Gen, 2007, 329, 46

46 C.G. Long, J.D. Gilbertson, G. Vijayaraghavan, K.J. Stevenson, C.J. Pursell and B.D. Chandler, J. Am. Chem. Soc., 2008, 130, 10103

47 M. Haruta, J. New Mater. Electrochem. Systems, 2004 , 7, 163

48 P. Mars and D.W. van Krevelen, Chem. Eng. Sci., 1954, 3, 41

49 P. Strathern, Mendeleev's Dream: the Quest for the Elements, Hamish Hamilton, London, 2000, p. $149 \mathrm{ff}$.
50 W.C. Ketchie, Y.-L. Fang, M.S. Wong, M. Murayama and R.J. Davis, J. Catal., 2007, 250, 94

51 F. Moreau and G.C. Bond, Catal Today, 2006, 114, 362

52 D. Ramdayal, J McPherson, T. Khumalo, G Pattrick and E. van der Lingen, Proc. GOLD 2009, Heidelberg, Germany, July 2009

53 L. An and C. Qi, CatGold News, p.2 in Gold Bull., 2008, $41 / 2$

54 N. Yang, CatGold News, p.1 in Gold Bull, 2008, 41/3

55 G.C. Bond and J.B.P. Tripathi, J. Chem. Soc. Faraday Trans. I, 1976, 72, 933

56 A. Kuperman and M.E. Moir, Chevron, WO Patent 2005/005032

57 G.C. Bond, Gold Bull., submitted

58 G.J. Hutchings, Chem. Commun., 2008, 1148

59 G.J. Hutchings, Catal. Today, 2008, 138, 9

60 J.K. Edwards and G.J. Hutchings, Angew. Chem. Int. Ed., 2008, 47, 9192

61 G.C. Bond, Catalysis by Metals, Academic Press, London, 1962, Ch.8

62 T.E. Wood, L.A. Brey, G.M. Buccellatto, G.D. Damte, D.D. Fansler, M.E. Jones and M.E. Müller, 3M, US Patent 2009011293 A1, 8 January 2009

63 B. Veeraraghavan, T.E. Wood, C.S. Chamberlain and S.A. Vanesse, WO Patent 2009/026035 A2, 26 February 2009 